\title{
Factors Contributing to Pupils' Poor Performance in Literature in English
}

\author{
Eddie Sing'alamba Mubita*, David Sani Mwanza \\ The University of Zambia
}

*Corresponding Author: Eddie Sing'alamba Mubita, The University of Zambia

\begin{abstract}
Literature in English is a beneficial subject to learners who take it. Unfortunately, the performance of learners in the subject in Western Province of Zambia has remained poor as evidenced by successive Examination Council of Zambia (ECZ) and chief markers performance reports. This article discusses the importance of literature and methods used in teaching it. It also presents the findings of a study which sought to establish the factors contributing to the poor performance of learners in the subject in relation to motivation. A study qualitative design was used employing a case study strategy of inquiry. 150 participants comprising 10 Heads of Literature and Language departments, 20 teachers of Literature, 100 Grade 12 learners of literature and 20 former learners who failed the subject were recruited for the study using purposive and snowball sampling techniques. The study established that teachers and learners faced a number of challenges such as inadequate teacher preparation, use of inappropriate techniques, negative attitudes and lack of teaching and learning resources. The study also established that motivation was a major factor. Arising from the findings, the study recommended retraining of teachers through CPD in order to build their capacity in the teaching of Literature in English.
\end{abstract}

Keywords: Zambia, Factors, Pupils, Literature in English, Examination, Performance, Teachers

\section{BACKGROUND TO THE STUDY}

The teaching of Literature in English in Zambian schools can be traced back to the colonial period. The subject was introduced by colonialists to equip natives with skills and competences which would enable them communicate effectively using the English Language medium (Mwape, 1984; Simuchimba, 2016). At that time, all learners were mandated to take the subject.

At present, Literature in English is taught as an elective subject in some Zambian secondary schools; it is only offered at senior secondary level (Grade $10-12$ ). The subject is allocated four periods per week. Each period lasts forty minutes. In total, the subject has 160 minutes per week (CDC, 2013; Simuchimba, 2016). Teachers of Literature in English are expected to help learners navigate through the set texts in order to fully comprehend the texts. They are also expected to avail learners an opportunity to interact with the texts by reading the texts in depth, not only for the purpose of passing the Literature final examinations, but more so to help them find pleasure in literary texts.

Literature in English is considered very beneficial to the learners who take it. El-Helou (2010) states that learners of literature are able to develop insightful responses, literal comprehension, personal connection, cross cultural themes, interpretations and evaluation of texts. Brumfit (1986) as cited in Shazu (2014) states that literature is a skills subject as it mainly focuses on the skills the learners acquire as opposed to the content. This implies that through the study of different texts, learners are able to acquire a number of skills and competences. Sanoto (2017) opines that in addition to improving on their acquisition of the English language, studying literature develops learners' fluency in language use and builds vocabulary.

Sanoto (2017) adds that the value of literature in society cannot be under-estimated. This is because of the fact that literature offers the learner various benefits and opportunities for development. Literature has a holistic coverage; it encompasses every aspect of human endeavor. There is no area of human existence one can think of which has not been reflected in literary works. Apart from that, through the study of literary works, learners are availed unique opportunities to develop their intellectual or cognitive faculties. El-Helou (2010:3) states that: 
Beyond language, literature provides students with important comprehension and analysis tools. Through literature students learn to identify and analyse conflicts, themes, issues, and characters. Good texts, whether classic or modern literature, contain some universal themes which apply to the students' present and future lives. Literature is also an entry into another culture.'

To this effect, the study of literature can go a long way in helping nurture individuals to possess skills and competences that will enable them become useful citizens in the modern society and contribute not only to development at various levels of human life but also to the resolution of conflicts in society. Kateregga (2014:26) states that 'as an aspect of society, literature can be used as a tool in the resolution of conflicts among individuals and nations.' This is especially so in the current dispensation where social and political disputes seem to be the order of the day in communities, nations and the world at large. Without doubt, possession of interpersonal and other social skills that help facilitate peaceful co-existence in society is a much needed quality presently.

Undoubtedly, the achievement of such values is important for the developmental aspirations of any nation, most especially, the developing ones. Thus, Zambia is equally in need of citizens who can contribute positively to its developmental agenda. To that effect, the Zambian (2006) 'Vision 2030' document (p.2), states that:

Zambians by 2030 , aspire to live in a strong and dynamic middle - income industrial nation that provides opportunities for improving the well-being of all, embodying values of socio-economic justice, underpinned by the principles of; (i) gender responsive sustainable development; (ii) democracy; (iii) respect for human rights; (iv) good traditional and family values; (v) positive attitude towards work; (vi) peaceful coexistence and; (vii) private-public partnerships.

Literature is one subject where a number of the above stated qualities and values are discovered and learnt as evidenced by the aims and objectives of the 2013 Literature in English Syllabus which stipulates that 'the general aim of Literature in English is to develop learners in the following realms: (i) Intellectual or cognitive (ii) Emotional or affective (iii) Linguistic or communication.' The syllabus further states that it 'must also help learners in the acquisition of knowledge, skills and positive attitudes and values of the society they live in.'

Despite these perceived benefits of teaching and learning Literature in English, learner performance in the subject is below the expected standards in Zambia in general, and Western Province in particular. Learner performance in national examinations has remained stagnantly poor (ECZ, 2017 Grade 12 Examination Highlights; Simuchimba, 2016). The failure percentages in Literature in English for the years 2013, 2014, 2015 and 2016 were 29.03\%, 21.05\%, $28.9 \%$ and $39.9 \%$ respectively. The 2017 Examination Council of Zambia (ECZ) Grade 12 Examinations Highlights show that 31,605 candidates sat for the Literature in English examination in 2017. Out of this figure, 17,506 candidates, translating to $55.30 \%$ obtained grades below credit level. On the other hand, 11,902 candidates, translating to $37.66 \%$ got fail grades. As a result, ECZ recommended that this (scenario) should be interrogated further to establish the factors that are contributing to poor performance of learners in the Grade Twelve Literature in English national examinations. Consequently, the report read in part as follows:

High failure rate were observed in Literature in English (37.66 \%) and Icibemba $(17.51 \%)$. The candidates' poor performance in Literature in English and Icibemba needs to be interrogated in order to dig out factors responsible for this scenario (ECZ, 2017 Highlights: 23).

From the table above, it can be observed that the biggest failure percentage was recorded in Literature in English at $37.66 \%$ followed by Icibemba at $17.51 \%$. The failure percentage in English language was only $9.51 \%$, which shows that learners performed better in English language than in Literature in English. 


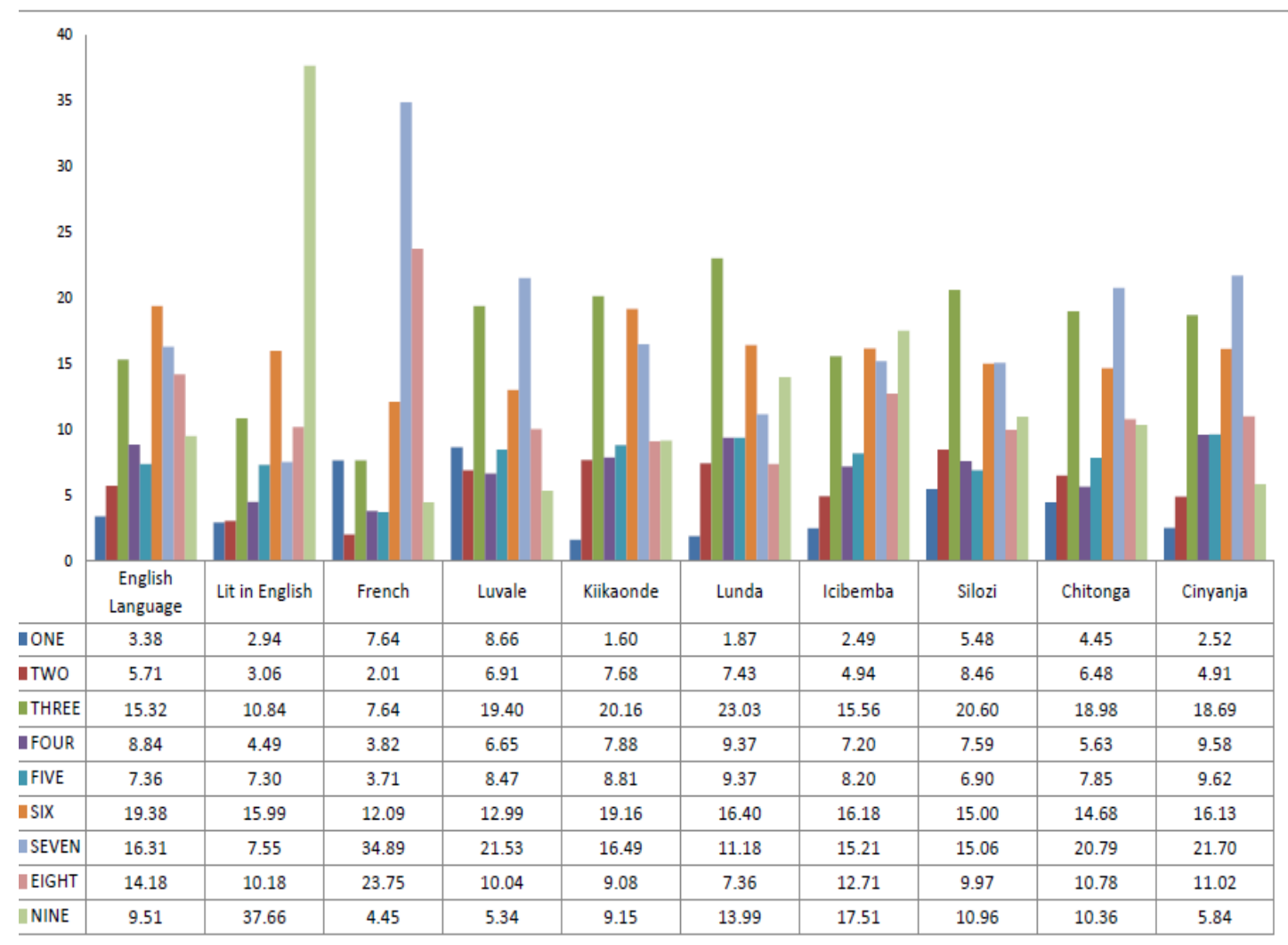

Fig1.1. Shows Performance of the 2017, Grade 12 candidates' in literature and languages.

\subsection{Statement of the Problem}

The 2017, Grade Twelve Examination Highlights by ECZ show poor performance of Grade 12 pupils in Literature in English. Simucimba (2016) indicates that Chief Examiners' reports and Examination Council of Zambia (ECZ) Performance reports from 2011 to 2015 show that the performance of candidates in Literature in English has remained stagnantly poor. Although the performance in literature has been low for a number of years as stated above, it is not known why Grade 12 pupils perform poorly in Literature in English in Western Province of Zambia. Stated as a question, the problem is: what are the factors contributing to poor performance of Grade 12 pupils in Literature in English examinations in Western Province of Zambia.

\subsection{Purpose of the Study}

The study sought to establish the factors that were contributing to poor performance of Grade 12 learners in Literature in English in 10 selected secondary schools of Western Province, Zambia.

\section{METHODS AND MATERIALS}

The study was guided by the social constructivist world view. In line with this, a qualitative research design employing a case study strategy of inquiry was used. The study site comprised five districts of Western Province of Zambia. Out of these, 10 secondary schools offering Literature in English were purposively sampled. The target population included all Heads of Literature and Language departments (HoDs), all teachers of Literature in English, all Grade 12 learners taking Literature in English and all former learners who failed the subject. The total sample size was 150 participants broken down as follows: $10 \mathrm{HoDs}, 20$ teachers of literature, 100 Grade 12 pupils taking literature and 20 former learners who failed the subject. The HoDs, teachers and Grade 12 learners taking literature were purposively sampled while the former learners who failed the subject were sampled using snowballing technique. The following instruments were: semi-structured interview guides and focus group discussion guides. A note book was also used to write down important points while an audiorecording device was used to record the interview sessions. Data was analysed qualitatively using emerging themes generated from the research findings. Trustworthiness of the findings was achieved through triangulation and member checks. 


\subsection{Presentation of Findings}

Data was obtained through interviews with HoDs, teachers of Literature in English, Grade 12 learners taking Literature in English and former pupils who failed Literature in English. The following subthemes were identified: inadequate teacher training, teachers' lack of subject background knowledge, inexperience, inappropriate teaching strategies, lack of materials, poor reading culture, inadequate preparation or training in answering questions, low proficiency levels in English on the part of learners, absenteeism and late-coming on the part of learners and negative attitude towards the subject. The factors are presented below as follows:

\subsection{Inadequate Teacher Training/ Preparation}

The data obtained from interviews with HoDs and teachers of Literature in English revealed that some teachers were not adequately prepared to teach Literature in English. For some, English was their minor teaching subject. Other respondents pointed out that Literature in English was treated as a component of English Language during their teacher training and that emphasis was placed more on English than on literature.

Consider the following responses:

Tr.1: ... I am prepared but not so much... in fourth year during my training, I switched to Religious Education. So, I did not continue with the literature courses. However, I am learning...

Tr. 2: Sir, literature is treated as a component of English in most training institutions. During my teacher training, more emphasis was placed on language teaching methodology. Not much was covered in terms of literature.

Tr. 3: In terms of being well prepared to teach literature, well, I should say I am trying to learn. Certain texts, say plays, are difficult to handle...

\subsection{Lack of Subject Background Knowledge}

Twelve out of the twenty teachers of literature interviewed indicated that they had no background of having taken literature during their secondary school education. The teachers stated that they mainly taught literature because of the passion they had for it. Consider the following responses:

Tr. 4: Well sir, eeeh, I did not take literature at secondary school level, but we were made to study a number of literature texts at university. Besides, I have passion for the subject. I think it also goes with passion.

Tr. 5: I enjoy very much and regret that if I had taken the subject at secondary level, I would do better. I enjoy that I am able to read many books I have not read before and different set ups of society... we are viewing the world in another way.

Tr. 6: Yes, I enjoy teaching literature. Though I never did it at secondary school, I liked reading. Reading is one of my hobbies. So, when I started doing it at university, I started enjoying it. What is bringing down that enthusiasm is the attitude of learners. They fear it. They say it is difficult.

\subsection{Inexperience of Some Teachers of Literature}

A number of teachers of literature had little experience of teaching Literature in English; seventeen teachers of literature had between one to five years' experience of teaching Literature in English. Among these were three teachers who were handling two Grade Twelve classes who had barely one year teaching experience at the time of the study. Consider the following verbatim responses by some teachers of literature:

Tr. 1: I started teaching literature last year. I was given a Grade 12 class for (name of a teacher) who went on leave...At first when I was given the class, I didn't have interest. Now, I feel it is coming. I was forced to teach literature by the authorities. They were saying it is a must since we have done English.

Tr. 2: Literature in English, I am just starting. I have been at a Basic school all along. I was transferred to this school in 2017 and I started teaching literature this year, 2019. 


\subsection{Use of Poor Teaching Strategies}

Despite the fact that most responses from teachers indicated that they mostly used learner-centred strategies, responses from former learners of Literature in English who failed the subject indicated that teacher-centred strategies were mainly used. Lesson observations also revealed that a number of teachers heavily relied on teacher-centred strategies such as question and answer and teacher exposition techniques leading to minimal or limited learner participation in lessons. Consider the following responses from former learners who failed the subject:

FP 1: Sometimes he (the teacher) would leave the book and tell us to read in his absence. Anyone would read.

FP 2: Literature in English is difficult. The reason why, we are from the rural area. We don't know English. Yes, when the teacher is reading the 'ka' book, we don't understand very well.

FP 3: The teacher is reading very fast. I am not understand. Some of us we are from the rural area.

FP 4: The teacher reading in class... No, only the teachers have the copy. Unless you pupils get the book which the teacher is using, you go and photocopy that's when you can access the whole class.

FP 5:... Almost all the time pupils used to exchange, this one reads and then that one. You can find that some, he or she don't know how to read, so he or she will jump other words which is difficult.

FP 6: We used to read during literature lessons. Sometimes the teacher would be around.

\subsection{Failure to Cover/ Complete Set Texts in Good Time}

Another factor that was identified was the issue of failure to cover all the set books before the time for the final examinations. This was revealed by both some former pupils as well as Grade 12 learners some of whom had barely completed the second text by term two of their final year. Consider the following responses:

FP 1: We did Animal Farm, Kongi's Harvest, Concubine and Things Fall Apart. These we finished. We did not finish the last book, the Enemy of the people because the teacher went for transfer.

P 1: We have done River Between. We started this in Grade 10. Grade Eleven, there were no books. We stopped literature in Term two of Grade 11. We started learning literature again this term. We have started Kongi's Harvest.

The above sentiment was also confirmed by the teacher who explained that she had been so frustrated by the unavailability of books that she almost advocated for the subject to be abandoned completely.

\subsection{Failure to Adequately Prepare Learners on How to Tackle Literature in English Questions in Good Time.}

Inadequate preparation or exposure of learners to examination type questions was another factor that was cited in interviews with Grade 12 learners of Literature in English and former learners who failed the subject. The respondents expressed the shock that learners or candidates get when seeing for the first time how questions are phrased in the mock or final examination papers. Consider the following responses:

P 1: Literature is one of the toughest subjects. In terms of writing tests, mid-term and end of term, we do pass, but when it comes to the final exams pupils fail.

FP 1: Yah, when it started, I was really enjoying. When I just wrote my mock, when I saw the questions how they came even my mind got disturbed. They gave us tests but I used to pass. But it came mock, that is where I started failing. Maybe they should start teaching pupils how they come questions just in Grade 10 not in Grade 12. It will be very difficult for them.

FP 2: It is a very difficult subject because of the upcoming of questions. They really confuse people. And there are so many books; there are like five books. 


\subsection{Low Literacy / Proficiency Levels of Learners}

One other challenge that became apparent was low literacy or proficiency levels of learners in English. Some learners were said to have problems with English. Focus group discussions with Grade 12 learners taking the subject also revealed that learners had challenges expressing themselves in English. Some former learners of the subject also raised this point. Consider the following responses:

$\operatorname{Tr} 1$ : Our learners come from rural areas; they find a lot of challenges in comprehending academic work...

$\operatorname{Tr} 2$ : Some learners are not able to read and write; illiteracy levels are simply high. So, if they cannot read and write, it is very difficult for them to perform well because the subject involves a lot of reading and writing.

$\operatorname{Tr} 3$ : The calibre of learners received in Grade 10 level, some of them don't seem to be able to read and write. The type of learners we receive, leave much to be desired.

P 1: The only problem which is there is lack of understanding. I find it difficult because of bombastic words.

FP 1: Literature in English is difficult. The reason why, we are from the rural area. We don't know English. Yes, when the teacher is reading the 'ka' book we don't understand very well.

FP 2: The teacher is reading very fast. I am not understand. Some of us we are from the rural area.

FP 3: I enjoyed the way it was starting. When it came to reading these books, it's when I was not understanding the books, maybe because of English.

\subsection{Absenteeism and Late Coming}

Absenteeism was cited as another factor contributing to poor performance of learners. According to the teacher respondents and former learners who failed the subject, some learners frequently absented themselves from literature lessons. This aspect was also witnessed in some lessons that were observed. In one lesson, only ten pupils out of a class of thirty-five attended the literature lesson. In another lesson for example, almost half of the pupils were missing from the lesson. Other learners came late for the lesson, some up to twenty (20) minutes after the lesson had started. Consider the following responses:

$\operatorname{Tr} 1$ : We have a big problem of truancy. If you do not come to school and don't read, how can you do well in the examination?

$\operatorname{Tr} 2$ : Another challenge is absenteeism. Most pupils abscond classes.

FP 1: I used to dodge from literature lessons because I did not understand what we were learning... I did not like the subject.

\subsection{Scarcity of teaching and learning materials}

Lack of teaching and learning resources was also cited as a factor by teachers and learners. Lesson observations also revealed this factor. For instance, in some of the classes where lessons were observed some teachers had only one (1) copy of the text under study for the whole class. In some cases, a few photocopies were shared among the learners. Consider the following responses from teacher respondents and former learners of the subject:

Tr. 1: Yah, I really enjoy it but what makes me to dislike it is what I have already explained lack of adequate materials.

Tr. 2: Literature is all about reading novels... a school like this one just has one copy for the entire school. Lack of materials makes the subject not to be interesting.

Tr. 3: As for me the way I have perceived the learners are not doing well in the subject maybe due to lack of teaching materials; text books are not enough. A teacher would just have one (1) copy to cater for everyone which is not possible. Pupils need to have hard copies.

FP 1: The teacher reading in class... No, only the teacher have the copy. Unless you pupils get the book which the teacher is using, you go and photocopy that's when you can access the whole class. 
FP 2: I wrote in 2018 and got a nine...maybe, because of the lack of books. You find that in class you are 40 of us but we are listening to one book from the teacher... we did not have money to buy 'ma' books.

\subsection{Negative Attitudes Towards Reading and Literature in English}

Negative attitude, especially among learners towards the subject, was also mentioned as one of the contributing factors to poor performance. This was also evident during lesson observations where, in some classes, high learner absenteeism and late coming were experienced. Consider the following responses

Tr. 1: Yes, I enjoy teaching literature. Though I never did it at secondary school, I liked reading. Reading is one of my hobbies. So, when I started doing it at university, I started enjoying it. What is bringing down that enthusiasm is the attitude of learners. They fear it. They say it is difficult.

Tr. 2: Because the books are not enough, most times it is the teacher reading the book. If you give them an assignment, they do not do because of low interest.

Tr. 3: What I have seen is some of the learners, the reading culture is poor. And then it is like if they are told that literature is hard, they have already convinced themselves that literature is hard because it involves reading a lot of books.

P 1: As for me, I am seeing that literature is a difficult subject. The words that we meet in literature, it is very hard to understand.

\subsection{Poor Reading Culture Among Learners}

Another factor that was cited and one that is closely connected to negative attitudes was poor reading culture among some learners and teachers. The following responses exemplify this fact:

Tr. 1: Very few of our learners enjoy the subject... the reason is poor reading culture. To me, they do not just enjoy reading.

Tr. 2: Generally, it is poor because of reading culture. Learners do not want to read. You have to push them; that is why the performance is poor, the other thing is lack of teaching and learning resources. That is a challenge.

Former learners who failed Literature in English also mentioned the problem of poor reading culture. Consider the following responses:

FP 1: No! Aaah, I don't like reading a lot of books.... Yes, I did not like the subject. .. I may say yes, because I had no choice; the class that I was in was taking literature and I had no choice. ...Aaah, No! I am not a fan of reading.

FP 2: ....Not at all, because as for we boys, we don't enjoy reading novels. I get bored.

In conclusion, the study established that teachers and learners were experiencing a number of challenges in the teaching and learning of Literature in English which probably contribute to poor performance of Grade 12 pupils in Literature in English national examinations. The following were the factors identified by the study: inadequate teacher training, teachers' lacking subject background knowledge, inexperience, use of inappropriate teaching strategies, lack of materials, poor reading culture, inadequate preparation or training in answering examination type questions, low learner proficiency levels in English, absenteeism and late-coming on the part of learners and negative attitude by both teachers and learners towards Literature in English.

\section{DISCUSSION OF FINDINGS}

The main focus of the study was to establish factors contributing to the poor performance of Grade 12 learners in Literature in English examinations in Western Province of Zambia. This was accomplished through face to face interviews with teachers of Literature in English; focus group discussions with Grade 12 learners; lesson observation and face to face interviews with former learners who failed the subject. The findings revealed that teachers and learners faced many challenges which probably contributed to the poor performance of Grade 12 pupils in Literature in English national examinations in Western Province of Zambia. The findings correspond to other studies on factors contributing to poor performance in English language and literature (cf. Işıklı, and Tarakçığlu, 2017; Anwar, 2017; Chazangwe, 2011). 
One of the findings was that a number of teachers of Literature in English were not adequately prepared to teach the subject. The finding correspond to (Chishipula, 2016; Mulenga, 2015; Mwanza, 2016; Işıklı and Tarakçıoglu, 2017; Sanoto, 2017). Furthermore, the findings revealed that more than half of the teachers of Literature in English lacked subject background knowledge as they did not take the subject during their secondary school education. The findings correspond to (Sanoto, 2017). Wampembe (2016) opined that the move which was taken making literature an optional subject deprived both teachers and learners opportunities for further, future development in the subject. Findings also revealed that some teachers had recently been promoted from primary schools to teach secondary school subjects such as English language and Literature in English. The study also established that seventeen out of the twenty teachers of Literature in English interviewed had less than five years' experience of teaching the subject. These factors probably accounted for the teachers' inability to use appropriate interactive teaching strategies. Although the study noted that no single method is simply the best in as far as the teaching of the subject is concerned, it was evident that a number of teachers lacked in terms of subject background knowledge, knowledge of pedagogy and experience. However, the fact that some teachers taught the subject out of passion implied that motivation played a significant role.

The study also established that some teachers held negative attitudes towards literature leading to inappropriate strategies (cf. Mwanza, 2016; Zulu, 2016; Chishipula, 2016; Simbeye, 2016) which in turn contributed to poor or negative attitudes on the part of learners. This was particularly noticed in literature lessons where a number of learners remained passive. Furthermore, some teachers claimed that they were forced to teach literature by their administrators, implying that some teachers viewed the subject negatively. Nonetheless, some teachers indicated that they had passion for teaching the subject though they did not have much subject background knowledge. Thus, it can be argued that there is a close connection between methodology in literature classes and motivational factors (cf. Kochhar, 1985).

Another aspect worth discussing and probably related to the aspect of negative attitudes is the question of poor reading culture of some teachers and learners. Some teachers and some former learners of literature indicated that they were not fans of reading implying that they did not read extensively. This corresponds to (Mubashir et al. 2015; Chazangwe, 2011; Simbeye, 2016). Extensive reading is considered a pre-requisite for a successful literature programme (see Sanoto, 2017). As remedy, Kateregga (2014) suggested the enhancement of a reading culture in learners early in the education system. The poor reading culture of some teachers was also evidenced by the fact that they only read the study texts at the same time as their pupils (during literature lessons) instead of doing so well in advance. Teachers with negative attitudes to literature would not love to read extensively resulting in their teaching methods suffering significantly as they would be limited in their knowledge and understanding of the texts. Consequently, it was highly likely that they transferred the same negativity to their pupils (cf. Sanoto, 2017). Learners with negative attitudes would normally remain passive in literature lessons, exhibit poor reading culture and ultimately perform poorly in examinations (Ackayir et al. 2016 cited by Abubakar, 2017).This finding entails that both teachers and learners require motivating. It is crucial that teachers demonstrate a love for reading to their learners because without it, they would only transfer negative attitudes.

The study further established that low literacy levels among learners were another challenge teachers faced. The findings correspond to (Chishipula, 2016; Ghazali, 2008; Simuchimba, 2016; Kateregga, 2014). This factor was also corroborated by former learners who failed the subject. Some former learners stated that they could not understand English as they were from rural areas. Kateregga (2014) suggests that teachers can speak to such learners using simple sentences while Ghazali (2008) recommends the use of various approaches such as extra classes or tuitions, organizing talks by speakers from similar backgrounds and getting support from the corporate sector to increase students' proficiency levels. Teachers who are well motivated are able to expend their energies to help learners facing difficulties if they are convinced that their efforts would be appreciated and yield positive results (cf. Maslow 1943; Mc Leod 2018).

The study also established that the problem of low proficiency levels in English among learners was aggravated by the lack of teaching and learning resources. A number of schools were experiencing serious shortage of texts under study. Four out of the ten study schools had only single copies of the texts being studied. The following were the texts that learners in the affected schools were studying: 
Song of Lawino, Mission to Kala, Romeo and Juliet and Kongi's Harvest. These are some of the texts that are usually considered quite difficult by teachers and learners. The finding concerning lack of teaching and learning materials corresponds to (Chazangwe, 2011; Işıklı, \& Tarakçığlu, 2017; Mwanza, 2016; Simbeye, 2016; Simuchimba, 2016 and Zulu, 2016). Most likely this (the scarcity of novels) impacted negatively on the choice of teaching strategies leading to poor lesson implementation. This is what probably led to teachers resorting to the use of teacher-centred techniques such as reading out to the learners since the learners did not have access to the novels for them to read in their spare time. As such, teaching strategies were greatly affected leading to negative attitudes by both teachers and learners. Additionally, in some institutions teachers seemed left alone to fend for themselves in as for as the search of set texts was concerned. It is important that teachers are supported by their administrators as this would make have a sense of belonging thereby contributing to their motivation (cf. Maslow's Hierarchy of needs). A motivated teacher would be able to diligently apply themselves to their tasks defying such odds (Bauer, 2016).

Another finding identified by the study which is probably linked to the use of inappropriate or poor strategies and attitudes was absenteeism and late coming by some Grade 12 learners. This problem was identified in at least three out of the ten literature lessons the researcher observed. In one of the classes, more than three quarters of the pupils were missing from the lesson when the lesson commenced. At the end of the period which was a double, only half of the learners were in class. The learners were probably not very passionate about learning the subject. Some former learners indicated that they used to dodge lessons owing to the fact that they found literature difficult and uninteresting. Poonam (2014) and Lewis (2017) propose the use of a multimodal approach involving the inclusion of ICT in literature lessons as a way of enhancing learner engagement and motivation. It has been established that the use of appropriate methods by teachers can help enhance learner engagement and interest in literature lessons thereby enhancing learner performance (see Ghazali, 2008).

The study further established that some teachers failed to complete the analysis of set texts in good time. By the end of Term One of Grade 12, one literature class at a certain school had barely commenced the analysis of the second set text implying that three texts had to be covered in the remaining two terms of Grade 12. It is very unlikely that learners can perform very well in such circumstances. Apparently, this could be attributed to the serious shortage of set texts. This factor was also noted by some former learners who failed literature. Most likely failure to complete the analysis of set texts in good time was one of the contributing factors to the poor performance of Grade 12 pupils in Literature in English examinations in some schools in the province. The study also established that another possible cause for the failure to finish the analysis of texts was the transfer or movement of teachers from one school to another.

Yet another factor that was identified was the failure to expose learners to examination type of questions in good time. This challenge was highlighted by former learners who failed literature. Some former learners attributed their failure to challenges they faced answering final examination questions. They indicated that learners should be exposed to examination type questions in good time. This finding somehow corresponds to (Mudenda, 1987; Simuchimba, 2016). Mudenda (1987) identified teachers' poor questioning technique as a factor affecting learner performance in literature. That study noted that teachers tended to use lower order type of questions in literature lessons. On the other hand, Simuchimba (2016) established that learners lacked adequate training in English academic writing. This can be attributed to teachers lacking adequate teacher preparation or training, basic subject background knowledge and experience.

The findings of this study have implications on teacher preparation and teacher/pupil attitudes. Firstly, some teachers do not possess the necessary skills to teach Literature in English. Since they are in service teachers, it is important that school or zonal based Continuing Professional Development trainings are conducted across the country in order to build the capacity of teachers to teach Literature in English. As Manchishi and Mwanza (2018) and Kombe and Mwanza (2019) pointed out, the quality of a teacher is a major factor in the effective teaching of any subject. Mwanza (2017) also asserts that lack of teachers' knowledge or understanding possess negative prospects towards the implementation of a school curriculum. Secondly, there is need for teachers and pupils to change their attitudes towards reading and the subject itself. Clearly, teachers' attitudes towards the subject or curriculum have far reaching consequences on the implementation of the curriculum (Mwanza, 2017). Similarly, the attitudes of pupils towards reading and the subject contribute significantly the failure 
rate being experienced in the subject. Thus, there is need to conduct motivational talks with both teachers and pupils on the importance of reading and Literature in English.

\section{CONCLUSION}

The study has established that teachers and learners of Literature in English face many challenges which impact negatively on the teaching and learning of the subject thereby contributing to poor performance of learners in Literature in English examinations in Western Province of Zambia. The challenges include inadequate teacher preparation; lack of subject background knowledge among most teachers; inexperience of some teachers; use of inappropriate teaching strategies; negative attitudes of teachers and learners towards the subject; poor reading culture among teachers and learners; low learner proficiency levels in English; lack of teaching and learning materials; absenteeism and late-coming among learners; failure to complete the analysis of set texts and failure to expose learners to examination type of questions in good time. The study contends that motivation is another key factor that influences the performance of teachers and learners in Literature in English.

\section{REFERENCES}

[1] Abubakar, J. A., G. V. Zulkifli, A. N Alwi, and R. C. Mat, A review of the motivation theories in learning. AIP Conference Proccedings 1891, 020043 (2017); doi 10.1063/1.5376.

[2] Anwar, S, Md. (2017) ESL/EFL learners' poor performance in English: The Factors. Journal of Asian and African Social Science and Humanities.

[3] Bauer, K. N., K.A. Orvis, K. Ely and E.A. Surface, Re-examination of motivation in learning contexts: Meta analytically investigating the role type of motivation plays in the prediction of key training outcomes. Journal of Business and Psychology, 31, 1, 33-50 (2016).

[4] Chazangwe, V. (2011). An Investigation into the factors for poor performance of grade twelve pupils in reading comprehension: A case study of selected High Schools in Kalomo District. A Masters Dissertation. Lusaka: UNZA.

[5] Chishipula, J. (2016). Factors Hindering Teachers of English Language from Implementing Communicative Language Teaching (CLT) Approach: A Case of Selected Secondary Schools in Chongwe District, Zambia. A Masters Dissertation. Lusaka: UNZA.

[6] El-Helou, H. A. R. (2010). Difficulties facing English Teachers in teaching Literature in English for Palestine grade twelve textbook. A Masters Dissertation. Gaza: The Islamic University.

[7] Examinations Council of Zambia. (2017). School Certificate Results (Highlights). Lusaka: ECZ.

[8] Ghazzali, S. N. Learner Background and their Attitudes towards Studying Literature. Malaysian Journal of ELT Research, Vol. 4, (2008).

[9] GRZ. (2006) Vision 2030. 'A prosperous middle - Income Nation by 2030.'

[10] Işıklı, C. and A.Ö. A.Ö. Tarakçıoğlu, (2017). Investigating problems of English literature teaching to EFL high school students in Turkey with focus on language proficiency. Journal of Language and Linguistic Studies, 13(2), 82-95.

[11] Kateregga, A. Towards a holistic approach of teaching and learning literature: Misconceptions about and endangerment of literature in Uganda's Schools. Synergies des Grands Lacs No. 3 - 2014. P. 25 - 34.

[12] Kochhar, S. K. (1985) Methods and Techniques of Teaching. New Delhi: Sterling Publishers (P) Ltd.

[13] Kombe, C., \& Mwanza, D.S. (2019). The 2014 Zambian Revised Literacy Policy in Primary Schools: Were Teachers Prepared to Implement It? International Journal of Humanities Social Sciences and Education (IJHSSE), 6(8), 115-131.

[14] Manchishi, P.C., \& Mwanza, D.S. (2018). Reforming School Experience in Pre-Service Teacher Preparation for Quality Teacher Graduates. Multidisciplinary Journal of Language and Social Sciences Education, 1(2), 1-26.

[15] Maslow, A. H. (1943). A Theory of Human Motivation. Psychological Review 50 (4), 370-96.

[16] McLeod, S. A. (2018, May 21). Maslow's hierarchy of needs. Retrieved from https://www.Simplypsyc hology .org/maslow.html. on 26/10/2018

[17] MESVTEE, (2013). Literature-in-English Syllabus. Grade10 -12. Lusaka: CDC.

[18] Mubashir, I., M. Noor, F. Muhabat and B. Kazemian. Factors Responsible for poor English Reading Comprehension at Secondary Level. Communication and Linguistics Studies. Vol.1, №1, 2015, pp.1-6. Doi:10.11648/j.cls.2015101:11.

[19] Mudenda, S. J. (1987). An Investigation of the Questioning Behaviour of Teachers of Literature in the classroom. A Masters Dissertation. Lusaka: UNZA. 
[20] Mulenga I. M. (2015). English Language Teacher Education Curriculum Designing; A Mixed Methods Analysis of the Program meme at the University of Zambia. A Doctoral Thesis. Lusaka: UNZA.

[21] Mwape, F. L. (1984). The Objectives of Teaching Literature in Zambian Secondary Schools and the Extent of their Attainment through the set Book syllabus. A Masters Dissertation. Lusaka: UNZA.

[22] Mwanza, D. S. (2016). A Critical Reflection on Eclecticism in the Teaching of English Grammar at selected Zambian Secondary Schools. A Doctoral Thesis. University of the Western Cape.

[23] Mwanza, D.S. (2017). Teachers' Understanding and Attitudes towards the Eclectic Method to Language Teaching in Zambia. Journal of Educational and Management Studies. 7 (1), 01-16.

[24] Mwanza, D.S. (2017). The Eclectic Method to language teaching: Clarifications and Conceptual Extensions. Journal of Lexicography and Terminology. 1 (2), 1-24.

[25] Sanoto, D. V. (2017). Teaching Literature to second Language Learners in Botswana Primary Schools: Exploring In-service Education and Training Teachers' classroom practices. A Doctoral Thesis. Gaborone: Stellenbosch University.

[26] Simbeye, R. M. (2016). Error Analysis of Grade 12 pupils in English Expository Compositions: A Case of Selected Secondary Schools in Nakonde District, Zambia. A Masters Dissertation. Lusaka: UNZA.

[27] Simuchimba, J. (2016). Factors contributing to poor performance of grade 12 learners at the national examination in Literature in English in secondary schools of Kafue district, Zambia. A Masters Dissertation. Lusaka: UNZA.

[28] Shazu, R. I. Use of Literature in Language Teaching and Learning: A Critical Assessment. Journal of Education and Practice. ISSN 2222- 1735 (Paper) ISSN 2222 - 288x (online) Vol. 5, No. 7, 2014.

[29] Wampembe, L. "Teaching of Literature in Zambian schools." Times of Zambia. Published by Lumba, H. on (June 11, 2016). Digital copy-downloaded from www.timesepaper.com. on 01/11/2018 at 11:06 hrs.

[30] Zulu, M. P. (2017). Teachers' Application of the Communicative Teaching approaches in selected secondary schools of Mufulira District, CopperBelt Zambia. A Masters Dissertation. Lusaka: UNZA.

Citation: Eddie Sing'alamba Mubita, David Sani Mwanza. "Factors Contributing to Pupils' Poor Performance in Literature in English" International Journal of Humanities Social Sciences and Education (IJHSSE), vol 7, no. 3, 2020, pp. 55-65. doi: http://dx.doi.org/10.20431/2349-0381.0703007.

Copyright: (c) 2020 Authors. This is an open-access article distributed under the terms of the Creative Commons Attribution License, which permits unrestricted use, distribution, and reproduction in any medium, provided the original author and source are credited. 